\title{
Book Review: Locales of Happiness: Colonial Irrigation in the Netherlands East Indies and its Remains, 1830-1980
}

\author{
M. Carey \\ Robert D. Clark Honors College, University of Oregon, Eugene, OR 97403, USA
}

Correspondence to: M. Carey (carey@uoregon.edu)

\begin{abstract}
Maurits Ertsen: Locales of Happiness: Colonial Irrigation in the Netherlands East Indies and its Remains, 1830-1980, VSSD, the Netherlands, 238 pp., ISBN-13: 978-90-6562241-9, US\$36.00, 2010.
\end{abstract}

Scholarship on colonial science, technology, and engineering has increasingly examined the ways in which expertise was not simply diffused from the metropolis in Western Europe but rather evolved based on local conditions and in dialogue with regional forces, conditions, and social groups in the colonies themselves. Scholars like Steven Shapin (1998) and David Livingstone (2003) have emphasized that science and technology have a geography - that knowledge varies in both time and space, and is influenced by specific issues in certain places, rather than being universal or placeless. Research on colonial science and technology has increasingly shown how innovations from within the colonies and by colonized populations have contributed to the global development of expertise. Kapil Raj (2007), for example, explicitly tries to "relocate modern science" by demonstrating how science evolved in colonial contexts and how dialogue among historical actors in places like India shaped knowledge development over time. In addition to emphasizing these colonial contributions to science and technology, recent scholarship has also seen a surge in understanding of the complex and multifaceted roles that engineers play in history. Martin Reuss (2008) argues that engineers have been intermediaries between a host of historical actors. These various advances in a diversity of historiographies demonstrate that an analysis of the evolution of colonial engineering practices reveals much more than a history of engineers. It also uncovers histories of human-environment interactions, colonial rule, export economies, farming and food production, and the flows of power in distinct empires.

Maurits Ertsen's book, Locales of Happiness, about the historical evolution of Dutch colonial irrigation practices in the East Indies is thus important well beyond its insights into the technical development and engineering history of irrigation practices. It has key implications for colonial policy and the way knowledge, engineering, and natural resource management evolved over time in colonial settings based on local factors such as crop choice, economic incentives, geography and terrain, imperial policies, and engineers' decision making. Moreover, Ertsen indicates the importance of his work because so much of the analysis of Dutch water management - not to mention hydraulic engineering itself - has focused on drainage, the removal of water to keep the sea out of the Netherlands. Much less scholarship focuses on irrigation and bringing water to certain areas. Yet Ertsen demonstrates compellingly that a rich history of Dutch expertise in irrigation exists, thereby complementing the longstanding focus on drainage.

Locales of Happiness achieves three major goals in its nine chapters that focus primarily on Dutch irrigation in colonial Indonesia since the early nineteenth century. First, the book begins with a substantive chapter that provides an overview of comparative nineteenth-century irrigation programs developed by colonial engineers in British India, French and British Africa (Sudan, Niger Delta, and North Africa), and the Netherlands East Indies. The chapter demonstrates not just the ways in which distinct colonies developed different irrigation practices, but also how those practices emerged from distinct political goals and agricultural or economic priorities within each colony. This overview explains the specifics of irrigation while contributing to scholarship on technological artifacts produced in social, political, 
and economic contexts. The second aspect of the book is its illumination of Dutch irrigation practices in the East Indies, especially the innovations that emerged between about 1920 and 1940, which built on previous advances but produced many excellent contributions in water management techniques. A third component addressed in the last two chapters focuses on irrigation education and the legacies of Dutch colonial irrigation practices in independent Indonesia after the 1940s. Dutch irrigation influences did not end when Indonesia became independent. As the independent nation resettled people in the Outer Islands, irrigation policies were integral parts of those migration programs. Between about 1950 and 1980, approximately 1 million people were resettled to these Outer Islands, where they required new irrigation projects. While influences from many countries affected those irrigation practices, the Dutch irrigation tactics previously used on Java became important, Ertsen shows, in the settling of Lampung and elsewhere.

One of Ertsen's key arguments is that certain farming practices shaped irrigation practices and related technologies over time. Most notably, he shows that in the East Indies sugar cane for the export economy and rice for subsistence and local consumption were grown in the same irrigated areas. Because these crops (and the objectives for planting them) required different flow rates at different times of the day and year, Dutch engineers developed many new innovations in flood gate and water flow technologies, in discharge measurement structures, and in the ability to calculate canal profiles. In short, irrigation developed in response to what Ertsen calls two types of "artifacts": management regulations and structures. Although there was discussion among distinct users in the evolution of these artifacts, civil servants tended to focus on regulations while engineers played the most decisive role in engineering structures.

Ertsen examines the role of these engineers rather than investigating the societal and political debates about water management. He traces these engineering developments after the late nineteenth century to show how Dutch experts targeted several aspects of irrigation technologies: water requirements; irrigation canals; structures of the irrigation system such as drops, checks, and discharge regulators; measuring structures such as intakes and gates; and canal water levels. In some cases, certain technologies were used not only to help expedite efficient water use, but also to reduce potential social conflicts among water users. The Begemann gate to automatically control water flow, for example, was developed in the East Indies, traveled to Nigeria, and then was brought back to the East Indies by a Dutch engineer in the 1970s. The goal of the gate was to maintain consistent upstream water levels and regulate water flows to reduce water conflicts among users. Ertsen provides meticulous detail about many other innovations in the regulation and measurement of water flows to suit both sugar cane and rice production in the East Indies, such as the refinement of capacity curves to estimate water flow capacities in irrigation canals or the development of the Romijn weir that modified the Verwoerd gate to both measure and discharge water without too much head loss. The second half of Locales of Happiness in particular provides extensive discussion about the specific irrigation practices that first evolved in the colonial East Indies and then persisted in independent Indonesia.

The book's principal strength is this level of detail, including many excellent diagrams, photographs, tables, mathematical formulae, and other images to thoroughly present the detailed knowledge that Dutch engineers developed, applied, adapted, and then taught about irrigation systems. Both engineers and historians of hydraulic engineering will benefit from Ertsen's extensive technical discussions of the technologies and artifacts used in the Dutch East Indies. The book also provides an excellent jumping off point for other studies as well since it inspires many interesting questions about topics such as: the social conflicts or political debates that stemmed from Dutch engineers' irrigation decisions in the East Indies; the ways irrigation practices affected livelihoods and societal conditions in areas surrounding irrigation projects; or the changing environmental conditions that affected water availability or the environmental impacts of new irrigation practices - topics that, for instance, Stefania Barca's (2010) book on water management in Italy and Donald Worster's (1992) classic Rivers of Empire on the Western United States have dealt with but not in the colonial context. These topics are obviously beyond the scope of Ertsen's book, and it is a sign of an effective book that it has laid the groundwork and raised additional questions about broader issues. Overall, Locales of Happiness is a solid book on the history of Dutch irrigation practices and engineering in the East Indies - a book that has an impressive level of detail about these innovations while suggesting broader implications for the relationships among irrigation, water management, crops, and colonial governance.

\section{References}

Barca, S.: Enclosing Water: Nature and Political Economy in a Mediterranean Valley, 1796-1916, White Horse Press, Cambridge, UK, 2010.

Livingstone, D. N.: Putting Science in Its Place: Geographies of Scientific Knowledge, University of Chicago Press, Chicago, Illinois, 2003.

Raj, K.: Relocating Modern Science: Circulation and the Construction of Knowledge in South Asia and Europe, 1650-1900, Palgrave MacMillan, New York, 2007.

Reuss, M.: Seeing Like an Engineer: Water Projects and the Mediation of the Incommensurable, Technol. Cult., 49, 531-546, 2008.

Shapin, S.: Placing the View from Nowhere: Historical and Sociological Problems in the Location of Science, T. I. Brit. Geogr., 23, 5-12, 1998.

Worster, D.: Rivers of Empire: Water, Aridity, and the Growth of the American West, Oxford University Press, New York, 1992. 